\title{
Effects of the hypoactive and inactive mutations on mating success in Drosophila melanogaster
}

\author{
Kevin O'Dell, ${ }^{*}+\ddagger$ \\ Barrie Burnet* and \\ Jean-Marc Jallon $\dagger$
}

\author{
* Department of Genetics, The University, Sheffield \\ S10 2TN, U.K. \\ $\dagger$ Laboratoire de Biologie et Genetique Evolutives, \\ CNRS, 91190 Gif-sur-Yvette, France.
}

The effects on mating success of four X-linked mutations controlling locomotor activity are examined. The mutation hypoE has no effect on female mating success. The mutations hypoC, iav and iav $^{2}$ reduce female mating propensity and extend courtship durations. Unlike wild type females these mutant females fail to reach their maximum propensity for mating on the second day after eclosion. The iav females have normal wild type compositions of cuticular hydrocarbons and are highly attractive to courting males. Attenuated perception or aberrant processing of male courtship stimuli, and delayed sexual maturation are likely contributors to the poor mating propensity of inactive females. The iav mutation also causes decreased mating success and extended courtship duration in male mutants. This is largely a consequence of their inactivity. The duration of courtship latency, which is related to the number of phenotypically inactive flies present in the pairing, is positively correlated with age. Copulation duration, though primarily a male determined trait, is also affected by age. Some inferences regarding possible modes of action of the mutations are discussed.

\section{INTRODUCTION}

Since the description by Sturtevant (1915), sexual behaviour of Drosophila has been the subject of reviews and investigations (see Burnet and Connolly, 1974; Ewing, 1983; Siegel et al., 1984). In Drosophila melanogaster the male orients himself towards the female and vibrates the wing nearest to her to produce a species specific song. He may then lick her genitalia, curl his abdomen and attempt to copulate.

Courtship behaviour involves visual, olfactory, tactile and auditory stimuli. Consequently there is a potentially large number of gene mutations likely to affect it. Spiess (1970) reviewed 20 investigations into the effects of specific single gene mutations on mating success. All the mutations were found to decrease mating success in males, whilst most mutant females showed reduced thresholds of receptivity. Two studies revealed that the mutations, cut (Merrell, 1949) and aristapedia (Tan, 1946), reduce female receptivity.

¥ Present address: Genetics Laboratory, Biochemistry Department, South Parks Road, Oxford OX1 3QU, UK. To whom correspondence should be addressed.
The effects of changes in locomotor activity on courtship behaviour have been examined using lines selected for high or low activity (Ewing, 1963; Kessler, 1968; Cook, 1973) and for fast or slow mating speed (Manning, 1961, 1963). Other than suggesting that the two systems are largely under independent genetic control, as Kyriacou (1981) noted, these studies show little agreement about the effects of activity on courtship behaviour. However, he concluded that there was some association between high activity and male mating success. More recently Cobb et al. (1987) found a correlation between high activity and short courtship latencies.

Gailey et al. (1986) report that the level of female locomotor activity decreases immediately prior to copulation. However, the precise role of locomotor activity throughout courtship remains unclear. This is surprising, given that during courtship transitions between male and female movement occur very frequently (Cobb et al., 1986). Once courtship has started, male locomotor activity is largely dependent upon that of the female (Cook, 1979). The amount of locomotion by females also affects the intensity of licking stimuli that they receive (Burnet et al., 1988). 
Single gene mutations controlling locomotor activity may also affect sexual behaviour. Homyk (1977) found that males with the X-linked mutations hypoactive- $B$ (now inactive ${ }^{2}$ ) and hypoactive$C$ showed "normal" wing vibration during courtship and proposed that the mutations were neurological in origin. The inactive females show a deficit in octopamine titre in the brain and other parts of the nervous system (O'Dell et al., 1987). More detailed information is required concerning the effect of these mutations on courtship behaviour and mating success. A description of the effects of four X-linked mutations hypoactive-C, hypoactive-E, inactive ${ }^{1}$ and inactive ${ }^{2}$ on locomotor activity has been given by O'Dell and Burnet (1988). The mutations cause changes in different specific aspects of locomotor activity such as amount or speed of movement and reactivity.

Any correlated change in mating success may direct attention to a relationship between particular aspects of locomotor activity and sexual behaviour. Such relationships may be revealed by the use of ethograms (Manning, 1959; Brown, 1964) and transition analyses of the sequential structure of specific courtship behaviours (Wood et al., 1980; Markow and Hansen, 1981; Cobb et al., 1986).

\section{MATERIALS AND METHODS}

The two wild type strains, Novosibirsk and Sierra Leone, and four mutants, hypoactive-C, hypoactive$E$, inactive ${ }^{1}$ and inactive ${ }^{2}$ used here have been described by O'Dell and Burnet (1988). As Spiess (1970) noted, comparisons between the effects of a mutant allele and its corresponding wild type allele may be obscured by the effects of differences in the residual background and the effects of inbreeding depression. The investigations using the inactive $^{1}$ mutation described here have been conducted using the $F_{1}$ hybrids derived from reciprocal crosses between two pairs of isogenic strains that differ only by the allelic substitution $\mathrm{iav}^{+}$or $i a v^{-}$(O'Dell and Burnet, 1988). The problems of genetic background and inbreeding depression can therefore be circumvented by comparing the behaviours of the hybrid wild type to the hybrid inactive flies so that differences in behaviour can more confidently be attributed to the effect of the iav locus itself.

Flies were raised on a standard oatmeal and molasses medium, seeded with live yeast and maintained at $25 \pm 0.5^{\circ} \mathrm{C}$ on a 12-hour light : dark cycle. The sexes were separated under ether on the day of eclosion and maintained in groups of ten in vials.

\section{Measurement of mating success}

Scores of mating success, courtship latency (time elapsing between the male and female being placed together and courtship beginning), courtship duration (the time elapsing between the beginning of courtship, defined as the first male wing vibration, and copulation irrespective of breaks in courtship), and copulation duration, were made using single pair matings with virgin flies.

Observations of courtship behaviour were made in a circular mating cell milled from a block of polythene and fitted with a clear Perspex lid. The cells were $21.5 \mathrm{~mm}$ in diameter and $4 \mathrm{~mm}$ deep and could be divided in half by a retractable divider. On opposite sides of this arena were $3 \mathrm{~mm}$ entrance holes, stoppered with a Perspex plug. The male was aspirated into one side of the divided cell and the female into the other. The flies were left for 1-2 minutes to recover from the aspiration. The cell divider was then retracted. Each pair was observed for three hours (at three days old), one hour (at the other ages), or until copulation occurred, whichever was the shorter. Durations were measured to the nearest minute. The initiation of courtship was defined by the first orientation of the male to the female in which wing vibration occurred.

\section{Analysis of courtship behaviour}

Courtship behaviour was observed at $8 \times$ magnification using a Nikon double-headed binocular stereo microscope under the conditions described above. The flies were observed from the start of courtship (defined as above) until copulation occurred, or until ten minutes of unsuccessful courtship had elapsed. If no courtship commenced within ten minutes the pair of flies were discarded.

The pattern of courtship events was recorded as the frequency and duration of key presses using an Apple II microcomputer as a data logger. Two observers recorded the fequency and duration of ten courtship elements on ten separate channels. One observer recorded the male behaviours of orientation, vibration, wing scissoring, licking and genital contact, whilst the other scored the female behaviours of movement, flicking, kicking, raising and extrusion. These behaviours have been described by Cobb et al. (1985).

In addition the sequences of courtship events during the observation period were compiled as a 
matrix. Wood et al. (1980), Markow and Hansen (1981) and Cobb et al. (1986) looked for significant transitions within matrices. However, this study is concerned with differences between transition matrices for courtship behaviour between wildtype and mutant. The emphasis is therefore on a comparison of the pattern and frequency of transitions between rather than within genotype groups and the results are presented in ethograms.

\section{Extraction of cuticular hydrocarbons}

Following the procedure of Jallon (1984), five individuals of each sex and genotype were bathed in $50 \mu \mathrm{l}$ hexane for five minutes and then vortexed. $5 \mu \mathrm{l}$ were then injected into a Girdel 300 gas chromatograph equipped with a Chrompack $25 \mathrm{~m}$ CpSil 5 capillary column. After integration with a Spectraphysics SP4270 integrator, chromatograms were compared within each group and with the reference chromatograms of $D$. melanogaster Canton-S males and females reported by Jallon (1984) and Antony et al. (1985).

\section{RESULTS}

\section{Mating success}

From the results in table 1 it is clear that three day old inactive males and females show reductions in mating success relative to the wild type control $\left(\chi^{2}=33.3, \mathrm{df}=1, P<0 \cdot 001\right)$, the effect in the female being particularly marked. The hypoC and $i a v^{2}$ females also show marked deficits in mating propensity but hypoE females are similar to wild type $\left(\chi^{2}=61 \cdot 8, \mathrm{df}=3, P<0 \cdot 001\right)$.
The mating success of wild type and iav at different ages is shown in fig. 1. The isogenised iav females show marked deficits in mating success throughout their lives. The developmental pattern of mating propensity is significantly different from that of wild type females $\left(\chi^{2}=84.01, \mathrm{df}=8, P<\right.$ $0 \cdot 001$ ), being characterised by an apparent delay in the attainment of maximum propensity.

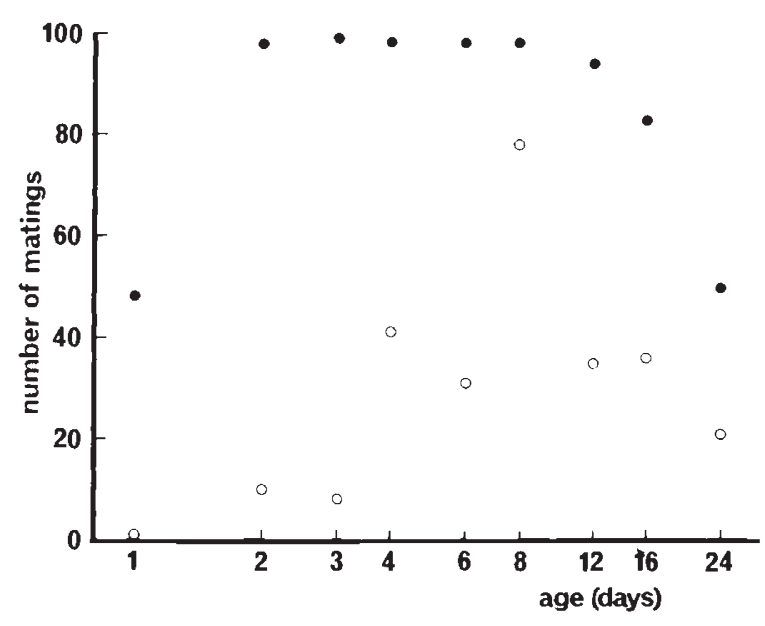

Figure 1 Relationship between mating success and age in isogenised wild type $(\bigcirc)$ and iav $(\bigcirc)$ females when paired to wild type males. $n=100$ for each point.

The effect of age on the mating success in the other mutant females is shown in fig. 2. The hypoE females show a wild type pattern of receptivity with age, but the consistently low frequency of mating by hypoC and $i a v^{2}$ females precludes any confident interpretation of temporal expression of sexual receptivity.

Table 1 Mating success and mean durations of latency, courtship and copulation in three day old flies in single pair mating trials over three hours. Mating success expressed as a percentage, durations of latency and courtship in log mins, duration of copulation in mins. For (a) $n=200$, (b) $n=100$, for durations of courtship and copulation $n=$ number mating within each class. Wild type is Novosibirsk inbred. Figures in parentheses are standard errors

\begin{tabular}{|c|c|c|c|c|c|}
\hline Female & Male & Success & Latency & Courtship & Copulation \\
\hline \multicolumn{6}{|l|}{$\mathbf{a}$} \\
\hline wild type & wild type & 94 & $0.061(0.010)$ & $0.601(0.030)$ & $23.67(0.34)$ \\
\hline$i a v$ & wild type & $35 \cdot 5$ & $0.332(0.028)$ & $1.274(0.057)$ & $23.83(0.50)$ \\
\hline wild type & iav & $77 \cdot 5$ & $0.242(0.024)$ & $1.376(0.033)$ & $18.45(0.44)$ \\
\hline$i a v$ & $i a v$ & 4 & $0.710(0.050)$ & $1.731(0.118)$ & $17 \cdot 50(1.94)$ \\
\hline \multicolumn{6}{|l|}{$b$} \\
\hline wild type & wild type & 92 & $0.089(0.018)$ & $0.878(0.051)$ & $25 \cdot 29(0.38)$ \\
\hline hypo C & wild type & 25 & $0.374(0.036)$ & $1.593(0.086)$ & $23.68(0.87)$ \\
\hline hypoE & wild type & 90 & $0.261(0.031)$ & $0.911(0.066)$ & $26 \cdot 41(0 \cdot 38)$ \\
\hline$i a v^{2}$ & wild type & 36 & $0.306(0.037)$ & $0.890(0.102)$ & $25.47(0.64)$ \\
\hline
\end{tabular}




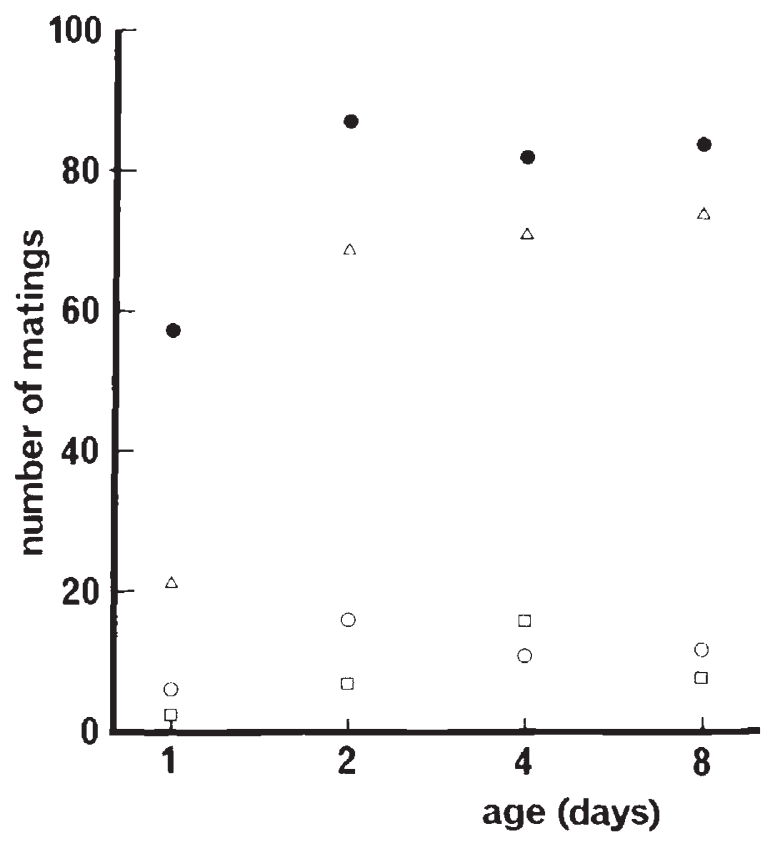

Figure 2 Relationship between mating success and age in hypoC $(\square)$, hypoE $(\triangle), \operatorname{iav}^{2}(\bigcirc)$ and Novosibirsk inbred wild type $(\bigcirc)$ females when paired with wild type males. $n=100$.

\section{Latency}

The effect of the mutations on courtship latency is shown in Table 1. Analysis of variance shows that the iav mutation extends the latency of both males ( $\mathrm{df}=1, F=79 \cdot 38, P<0.001)$ and females $(\mathrm{df}=1, F=138.59, P<0.001)$. The durations of latency for hypoC $(t=2 \cdot 85, P<0.001)$, hypoE $(t=$ $2.49, \quad P<0.05)$ and $\operatorname{iav}^{2} \quad(t=2.61, \quad P<0.05)$ females are all significantly longer than wild type.

Latency clearly varies according to the number of phenotypically inactive flies present in the pairing. The shortest latencies are shown by the wild type pairings, whereas the iav pairs show extended latencies. Those crosses involving one wild type and one phenotypically inactive individual are intermediate.

These results are confirmed and extended by the results presented in fig. 3. There is a clear relationship between latency duration and age. Both wild type ( $\mathrm{df}=1, F=29 \cdot 34, P<0 \cdot 001)$ and iav $(\mathrm{df}=1, F=7.87, P<0.001)$ females showing significant increases in latency with age.

\section{Courtship duration}

The effects of the mutations on courtship duration are shown in table 1 . Both iav males $(\mathrm{df}=1, F=$

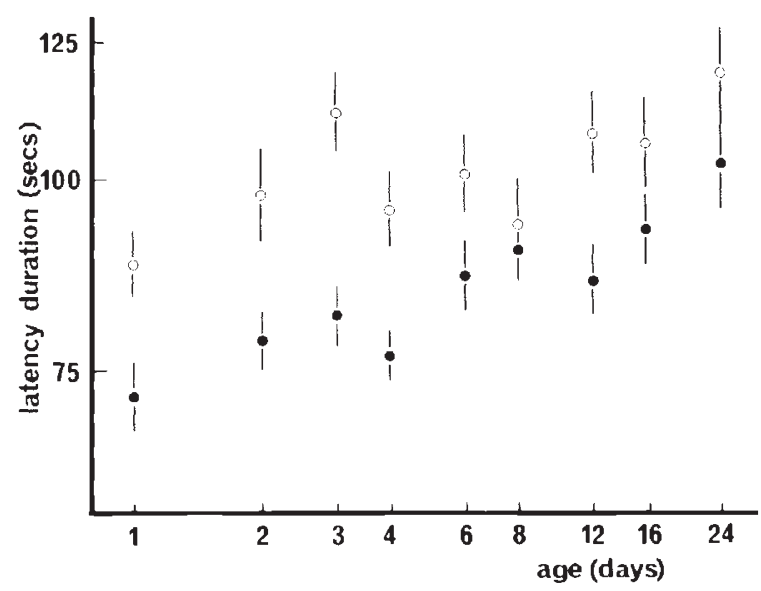

Figure 3 Relationship between latency duration and age in isogenised wild type (O) and iav (O) females when paired with wild type males. $n=100$.

$286 \cdot 14, P<0 \cdot 001)$ and females $(\mathrm{df}=1, F=48 \cdot 24$, $P<0.001)$ and also hypo $C$ females $(t=5.68, P<$ $0.001)$ have significantly extended courtship durations, but neither hypoE $(t=0 \cdot 40, \mathrm{~ns})$ nor $i a v^{2}$ $(t=0 \cdot 11$, ns $)$ females show any significant difference from wild type females. However, when results are pooled over different age groups $i a v^{2}$ females show significantly extended courtship durations $(t=3 \cdot 82, P<0 \cdot 001)$.

Wild type females have long courtship durations on the first day after eclosion, but consistently shorter durations thereafter (fig. 4). This first day level is comparable with the durations of isogenised iav females which are consistent from day 2 to day 32 .

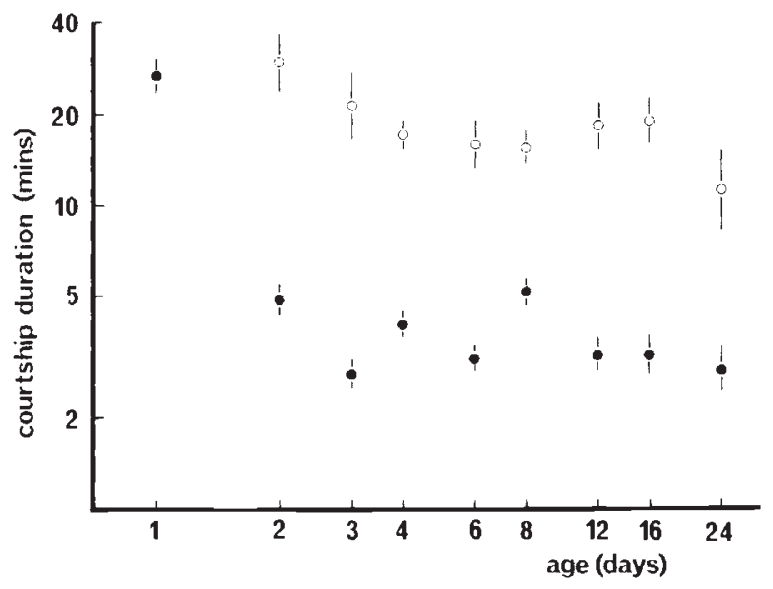

Figure 4 Relationship between courtship duration and age in isogenised wild type (O) and iav (O) females when paired with wild type males. $n=$ number of pairs mating, (see fig 1). 
The effects of age on courtship durations for the other mutants is shown in fig. 5. The hypoE females clearly show a wild type pattern of courtship duration with age. There may be some decrease in courtship duration as $i a v^{2}$ females age, but the low frequency of matings by one day old $h y p o C, i a v$ and $i a v^{2}$ flies preclude any meaningful comparisons at this age.

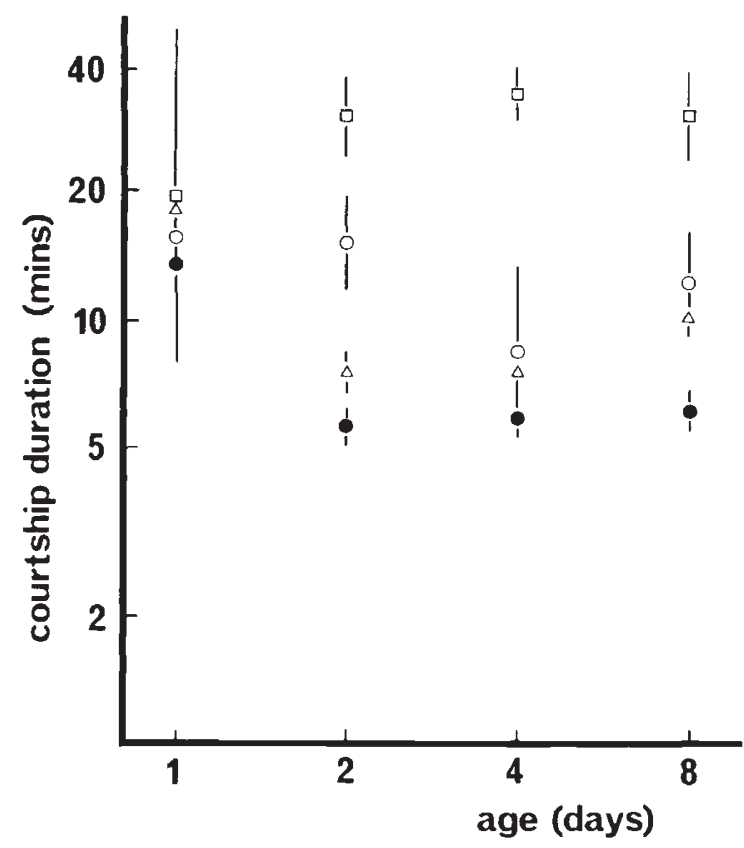

Figure 5 Relationship between courtship duration and age in hypoC $(\square)$, hypoE $(\triangle), i^{2} v^{2}(O)$ and Novosibirsk inbred wild type (O) females when paired with wild type males. $n=$ number of pairs mating, (see fig. 2).

\section{Copulation duration}

The effects of the mutations on copulation duration are shown in table 1. The iav males have a significantly shorter copulation duration than wild type males $(\mathrm{df}=1, F=109 \cdot 11, P<0.001)$. Fig. 6 shows the effect of age on copulation duration. Both wild type and iav females show very similar patterns of expression.

\section{Courtship behaviour}

Ethograms describing courtship are shown in fig. 7(a)-(c). The male maintains a position close to the female with his body axis oriented towards her. If she moves, he follows, so that during courtship his locomotor activity is largely dependent on that of the female. For wild type flies (fig. 7(a)) the

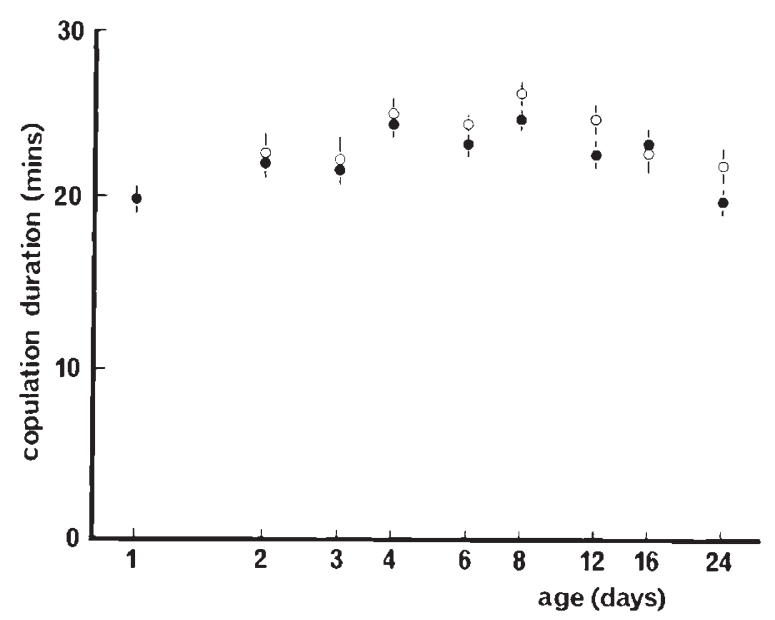

Figure 6 Relationship between copulation duration and age in isogenised wild type (O) and iav (O) females when paired with wild type males. $n=$ number of pairs mating, (see fig. 1).

most frequent transitions are those between moving and standing by the female $(12 \cdot 2$ and $11 \cdot 2$ per cent) indicating that much of the courtship time is spent in motion. Other important transitions include vibration-locking $(9.4$ per cent) and moving-vibration $(7 \cdot 8$ per cent), whereas the reverse transitions occur relatively inf requently (1.9 and 1.9 per cent). The licking-genital contact transition $(2 \cdot 2$ per cent $)$ indicates that wild type courtship is characterised by the sequence: vibration-lickinggenital contact.

The most frequent transition for the inactive female and wild type male pairings (fig. $7(\mathrm{~b})$ ) is from vibration to licking, suggesting that much of courtship time is spent in close contact. Analyses of variance show that, relative to the wild type females, iav females elicit significantly more vibration from the courting male over the ten minute observation period $(F=23.45, \mathrm{df}=1, P<0.001)$, and respond with significantly more kicking and fending $(F=14.52, \mathrm{df}=1, P<0.001)$. There are fewer movement transitions than in wild type courtships (5.8 and $4 \cdot 1$ per cent), and a low frequency of orientation-vibration transitions $(0 \cdot 6$ per cent), suggesting that there is little locomotor activity and few breaks in courtship. Lickinggenital contact transitions are infrequent $(0 \cdot 3$ per cent), whereas those from scissoring to vibration are relatively more frequent $(3 \cdot 3$ per cent).

The most frequent transitions for the wild type female and inactive male pairings (fig. $7(\mathrm{c})$ ) are those involving movement ( 9.3 and 7.8 per cent). The inactive males show a low frequency of transitions from moving to vibration $(4 \cdot 8$ per cent $)$ and 

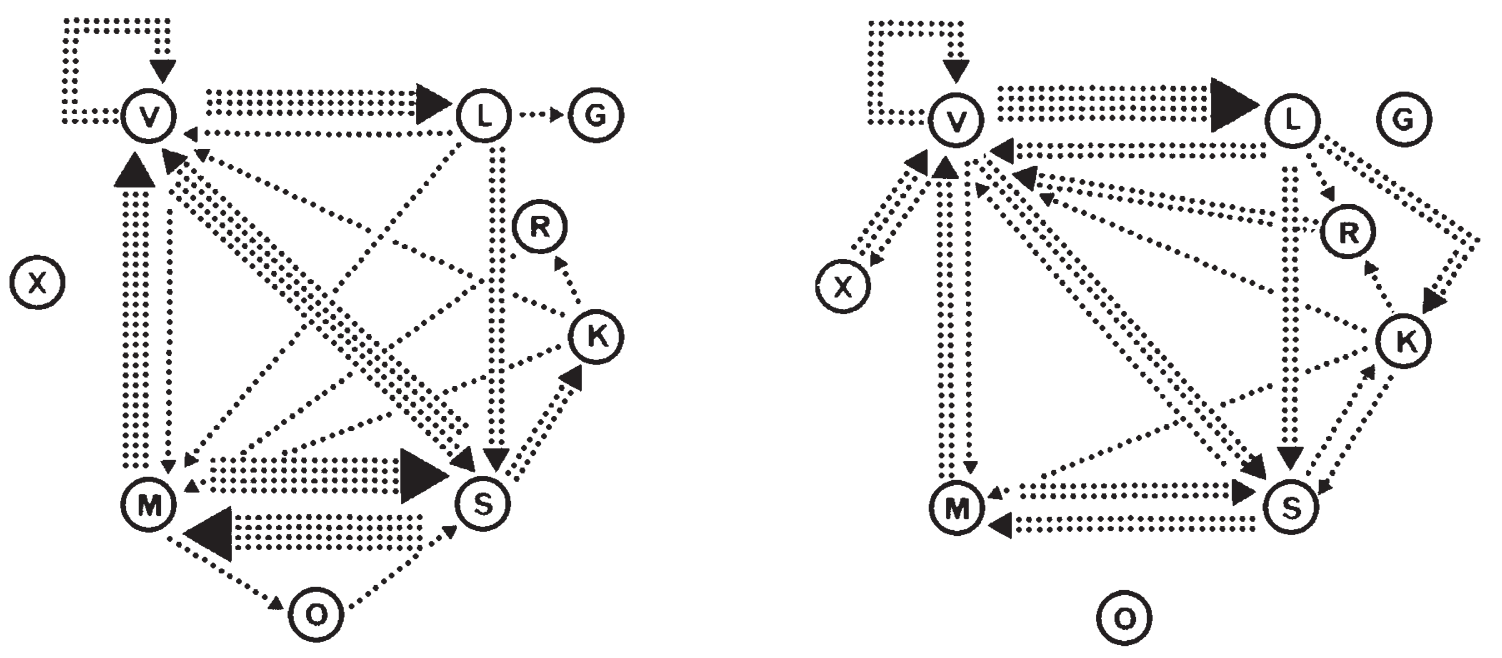

(A)

(B)

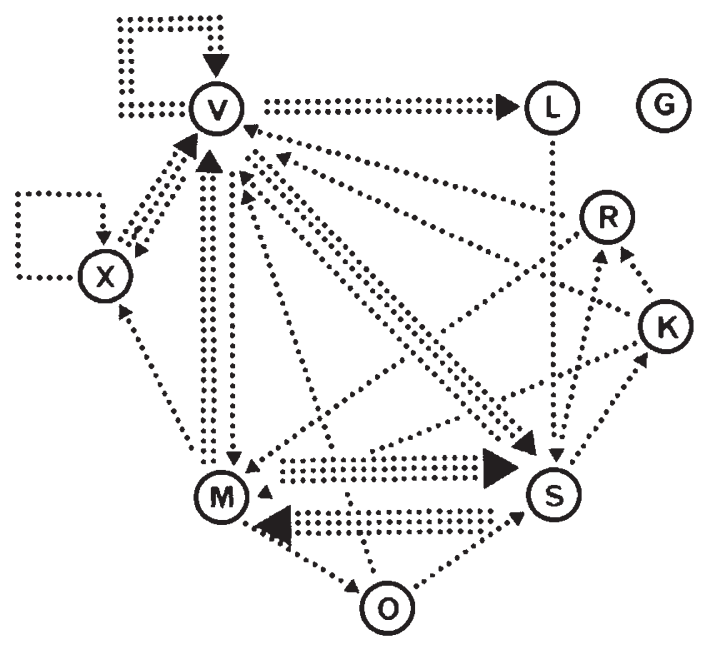

$G=$ Genital contact.
$K=$ Kicking.
$L=$ Licking.
$M=$ Moving.
$O=$ Orientation.
$R=$ Raising.
$S=$ Standing.
$V=$ Vibration.
$X=$ Wing Scissoring
$\cdots \cdots>1.5 \quad::::::>2.5 \quad::::::>6.5 \quad::::::>9.5$

(C)

Figure 7A-C Ethogram $(10 \times 10$ matrix) for courtship in Drosophila melanogaster. Frequency of transitions (per cent) denoted by thickness of arrow. A, female wild type $\times$ male wild type. $B$, female iav $\times$ male wild type. $C$, female wild type $\times$ male iav.

vibration to licking $(5 \cdot 8$ per cent). No transitions associated with genital contact occur at a frequency of greater than 1.5 per cent over the ten minute observation period. In addition the inactive males show transitions between scissoring and vibration ( 3.3 and 1.5 per cent), and following female movement $(2 \cdot 0$ per cent $)$. They also show recurrence of scissoring $(2 \cdot 0$ per cent $)$.

\section{Pheromones and other cuticular hydrocarbons}

Gas chromatographic analyses on a capillary column using hexane extracts from wild type and inactive individuals of both sexes were compared with those for Canton-S wild type flies described previously (Jallon, 1984). All major peaks comigrated with those of the reference strain. The 
Table 2 Cuticular hydrocarbon compositions of wild type and inactive males and females from the Novosibirsk background. Expressed as percentage of all characterised hydrocarbons with standard error

\begin{tabular}{|c|c|c|c|c|}
\hline $\begin{array}{l}\text { Hydrocarbon } \\
\text { percentage }\end{array}$ & Niav + female & Niav-female & $\mathrm{Niav}+$ male & $\mathrm{Niav}$-male \\
\hline 7-tricosene & $2.8 \pm 0.6$ & $2.8 \pm 0.7$ & $46 \cdot 2 \pm 1 \cdot 8$ & $44 \cdot 1 \pm 2 \cdot 8$ \\
\hline$n$-tricosane & $11 \cdot 6 \pm 1 \cdot 4$ & $9 \cdot 6 \pm 0.9$ & $16 \cdot 5 \pm 1 \cdot 4$ & $14 \cdot 2 \pm 1 \cdot 2$ \\
\hline 7-pentacosene & $3 \cdot 9 \pm 0 \cdot 5$ & $4 \cdot 7 \pm 0 \cdot 6$ & $5 \cdot 9 \pm 2 \cdot 0$ & $10 \cdot 0 \pm 0 \cdot 2$ \\
\hline$n$-pentacosane & $6 \cdot 3 \pm 0.9$ & $5 \cdot 7 \pm 0 \cdot 8$ & $4 \cdot 6 \pm 1 \cdot 8$ & $3 \cdot 0 \pm 0 \cdot 3$ \\
\hline 7, 11-heptacosadiene & $24 \cdot 1 \pm 2 \cdot 0$ & $23 \cdot 8 \pm 1 \cdot 2$ & & \\
\hline 2-methyl-hexacosane & $15 \cdot 7 \pm 0 \cdot 5$ & $15 \cdot 3 \pm 0 \cdot 4$ & $7.7 \pm 0.9$ & $7 \cdot 5 \pm 0 \cdot 9$ \\
\hline 7,11 -nonacosadiene & $10 \cdot 9 \pm 2 \cdot 8$ & $13 \cdot 4 \pm 1 \cdot 5$ & & \\
\hline 2-methyl-octacosane & $7.4 \pm 1.0$ & $7.0 \pm 0.9$ & $6.4 \pm 0.4$ & $6.9 \pm 1.1$ \\
\hline
\end{tabular}

mean percentages of the major components are listed in table 2. In the Novosibirsk genetic background, no marked quantiative differences were found between wild type and inactive. Most importantly no differences were found in the relative abundance of 7,11-heptacosadiene, the major pheromone of $D$. melanogaster (Antony et al., 1985). In addition no clear differences were found in any cuticular component between wild type and inactive males, nor females, within the Sierra Leone genetic background (data not shown).

\section{DISCUSSION}

According to Manning (1967), female receptivity is affected by two independent processes, "switchon" and summation. Switch-on is associated with female sexual maturity and determines whether the female is in the right physiological state to mate and sexually attractive to the courting male. Summation is connected with the amount of courtship stimulation required by the female before she copulates. Low female mating propensity could be determined by any of these processes.

Wild type females show a pattern of receptivity similar to that described by Manning (1967). However, their extended courtship durations on day 1 support the conclusions of Cook (1973). Mating propensity and courtship duration in young adult females are negatively correlated, suggesting that switch-on and summation are not entirely independent processes.

With the exception of the duration of latency, the courtship behaviour of hypoE females appears to be indistinguishable from wild type. This mutation is known to cause a deficit in speed but not amount of movement (O'Dell and Burnet, 1988). The hypoC, iav and $i a v^{2}$ females show deficits in mating propensity and extended courtship dur- ations. They also show reduced speed and amount of movement (O'Dell and Burnet, 1988) which suggests that there is an association between amount of locomotor activity and mating success.

Contrary to the criticisms of Robertson (1982), Manning's (1967) assertion that Drosophila courtship has a stimulatory function is supported by evidence presented by Cobb et al. $(1986,1987)$. Low mating propensity and extended courtship durations characteristic of hypoC, iav and $i a v^{2}$ mutants may be the consequence of aberrant female summation of male courtship stimuli. This could result either from attenuated perception or abnormal processing of the male courtship stimuli.

Through mosaic analysis and fate mapping Homyk (1977) proposed that the foci for aberrant locomotor activity in both hypoC and $i a v^{2}$ are neurological, the former in the suboesophageal ganglion and the latter in the thoracic ganglion. Such observations are consistent with poor summation through aberrant processing of courtship stimuli associated with some generalised neural defect. O'Dell et al. (1987) found that, relative to wild type females, iav mutants have significantly lower levels of octopamine in the brain as well as other parts of the nervous system, which is consistent with a neural effect of this mutation.

Another possibility is that the mutant females may be relatively unattractive. The two major components of female attractiveness are chemical and locomotor. The chemical component has been analysed in detail by Antony and Jallon (1982) and Antony et al. (1985). The most abundant epicuticular hydrocarbon found in mature wild type D. melanogaster females has a chain 27 carbons long with double bonds in positions 7 and 11 . This is absent in mature conspecific males and in females of the sibling species $D$. simulans. The abundance of this hydrocarbon in mature (4 day old) inactive females seems normal. 
According to Tompkins et al. (1982) and Jallon (1984) males need to perceive female movement to initiate courtship and court immobilised females with far less intensity than wild type females. This contrasts the findings of Bastock (1956), Ewing (1963) and Kyriacou et al. (1978) who noted that males direct a greater intensity of courtship to stationary females. Males have even been known to copulate at low frequencies with etherised (Streisinger, 1948) and decapitated (Spieth, 1966) females.

Female movement during courtship is important to the male, initially as a stimulator to initiate courtship. Subsequently, reduction or cessation of female movement may serve as a signal of acceptance (Tompkins et al., 1982; Gailey et al., 1986; Cobb et al., 1986). The inactive females may be providing the males with an inappropriate response, indicating that she is about to mate when in fact she is not. This appears to change the male's behaviour to a frustration response characterised by high levels of scissoring.

Courtships involving inactive females are characterised by reduced locomotor activity, and high frequencies of male vibration and licking. The frequent rejection responses, and low rates of genital contact suggest that the inactive females are unreceptive rather than unattractive.

The developmental changes in iav female mating propensity indicate that there may be some delay in switch-on. A similar delay in the onset of maximum levels of activity in iav mutants has been reported (O'Dell and Burnet, 1988). The extended courtship durations of iav females are remarkably similar to those of immature (one day old) wild type females, suggesting a possible association between sexual immaturity and courtship behaviour in three day old inactive females.

Mature inactive females have a cuticular hydrocarbon profile that is very different from that in young flies which exhibit non-sex-specific compounds that disappear about $24 \mathrm{hrs}$ after eclosion (Antony and Jallon, 1981; Pechine et al., 1988), and this is also the case for cuticular hydrocarbons of inactive males. Retention of an immature hydrocarbon pattern has been found in apterous -4 males (Jallon et al., 1986). However, this does not preclude the possibility of a short delay in maturation of inactive females as it is not yet clear whether the switch-on of female receptivity is temporally linked to changes in the female's pheromone coat.

The relative contribution of poor neural processing and sexual immaturity to the poor mating success of these mutant females requires further examination. It is quite possible that a primary neural focus could be a common factor underlying both effects. This is supported by Homyk (1977), who found a thoracic neural focus for aberrant locomotor activity, and by O'Dell et al. (1987) who found a deficit in the neurotransmitter octopamine in inactive females. The corpora cardiaca and corpora allata associated juvenile hormone release, and sexual maturation in several insect species, are known to be octopaminergic (Evans, 1980).

The inactive males are characterised by deficits in several aspects of locomotor activity (O'Dell and Burnet, 1988). Decreased mating success, and increases in the durations of latency and courtship may be a direct consequence of reduced activity. Mutant male courtship behaviour is characterised by frequent breaks from close contact with the female, low incidence of genital contact and an increased frequency of scissoring. This latter behaviour is rare in wild type males and is characteristic of prolonged unsuccessful courtship, indicating that it may be a frustration response. This strongly supports the notion that inactivity is the major contributory factor in the poor mating success of the inactive males. However, in the light of the observations on the iav females the actual situation is probably more complex.

The observation that latency is associated with the number of phenotypically inactive flies present in a pairing agrees with that of Cobb et al. (1987), who found an inverse relationship between activity and courtship latency in the melanogaster species subgroup. However, the positive correlation between latency and age is not in accord with that observed by Eastwood and Burnet (1977) and Cobb et al. (1987), although this may be a consequence of the different age ranges investigated.

MacBean and Parsons (1967) noted that copulation duration is primarily a male determined trait, which our results confirm, although there is some effect of age.

The reduced mating success of $i a v$ females, and to a lesser extent of iav males, appears to be a direct consequence of some neurological effect of the mutation rather than a secondary effect of reduced locomotor activity per se, but the precise mode of action of the mutation requires further investigation.

Acknowledgements This investigation was carried out during tenure by K. O'Dell of a postgraduate training award from the Science and Engineering Research Council, UK, and with support from the Centre National de la Recherche Scientifique, France, whilst at Gif-sur-Yvette, which is gratefully acknowledged. 


\section{REFERENCES}

ANTONY, C., DAVIES, T. L., CARLSON, D. A., PECHINE, J. H AND JALLON, J-M. 1985. Compared behavioural responses of male Drosophila melanogaster (Canton-S) to natural and synthetic aphrodisiacs. J. Chem. Ecol., 11, 1617-1629.

ANTONY, C. AND JALlON, J-M. 1981. Evolution des hydrocarbones comportementalement actifs de Drosophila melanogaster au cours de la maturation sexuelle. C.R. Acad. Sci. Paris, 252, 239-242.

ANTONY, C. AND JALLON, J-M. 1982. The chemical basis for sex recognition in Drosophila melanogaster. J. Insect Physiol., 28, 873-880.

BASTOCK, M. 1956. A gene mutation which changes a behavior pattern. Evolution, 10, 421-439.

BROWN, R. G. B. 1964. Courtship behaviour in the Drosophila obscura group. Part I: Drosophila pseudoobscura. Behaviour, 23, 61-106.

BURNET, B., AND CONNOLly, K. J. 1974. Activity and Sexual Behaviour in Drosophila melanogaster. In van Abeelen, J.H.F. (ed.) The Genetics of Behaviour, North-Holland, Amsterdam, pp. 201-258.

BURNET, B., BURNET, L., CONNOLLY, K. J. AND WILLIAMSON, N. J. 1988. A genetic analysis of locomotor activity in Drosophila melanogaster. Heredity, 61, 111-119.

COBB, M., BURNET, B. AND CONNOLLY, K. J. 1986. The structure of courtship in the Drosophila melanogaster species subgroup. Behaviour, 97, 182-212.

COBB, M., CONNOLly, K. J. AND BURNET, B. 1985. Courtship behaviour in the melanogaster subgroup of Drosophila. Behaviour, 95, 203-231.

COBB, M., CONNOlly, K. J. AND BURNeT, B. 1987. The relationship between locomotor activity and courtship in the melanogaster species subgroup of Drosophila. Anim. Behav., 35, 705-713.

COOK, R. M. 1973. Physiological factors in the courtship processing of Drosophila melanogaster. J. Insect Physiol, 19, $397-406$.

COOK, R. M. 1979. The courtship tracking of Drosophila melanogaster. Biol. Cybernet., 34, 91-106.

EASTWOOD, W. L. AND BURNET, B. 1977. Courtship latency in male Drosophila melanogaster. Behav. Genet., 7, 359-372.

EVANS, P. D. 1980. Biogenic amines in the insect nervous system. Adv. Insect Physiol., 15, 317-473.

EWING, A. W. 1963. Attempts to select for spontaneous activity in Drosophila melanogaster. Anim. Behav., 11, 369-378.

EWING, A. W. 1983. Functional aspects of Drosophila courtship. Biol. Rev., 58, 27.5-329.

GAILEY, D. A., JACKSON, F. R. AND SIEGEL, R. W. 1982. Male courtship in Drosophila: the conditioned response to immature males and its genetic control. Genetics, 102, $771-782$.

GAIlEY, D. A., LACAIllade, R. C. AND HALL, J. C. 1986. Chemosensory elements of courtship in normal and mutant, olfaction-deficient Drosophila melanogaster. Behav. Genet., 16, 375-405.

HOMYK, T. 1977. Behavioral mutants of Drosophila melanogaster. II. Behavioral analysis and focus mapping. Genetics, 87, 105-128.

JALLON, J-M. 1984. A few chemical words exchanged by Drosophila during courtship and mating. Behav. Genet. 14, 441-478.

JALLON, J-M., ANTONY, C., CHAN-YONG, T. P. AND MANIER, S. 1986. Genetic factors controlling the production of aphrodisiac substances in Drosophila. In Porchet, M., Andrues, J. C. and Dhainaut, A. (eds.) Advances in Invertebrate Reproduction 4, Elsevier, Amsterdam, pp. 445-452.
KESSLER, S. 1968. The genetics of Drosophila mating behaviour. I. Organisation of mating speed in Drosophila pseudoobscura. Anim. Behav., 16, 485-491.

KYRIACOU, C. P. 1981. The relationship between locomotor activity and sexual behaviour in ebony strains of Drosophila melanogaster. Anim. Behav., 29, 462-471.

KYRIACOU, C. P., BURNET, B. AND CONNOLLY, K. J. (1978). The behavioural basis of overdominance in competitive mating success at the ebony locus of Drosophila melanogaster. Anim. Behav., 26, 1195-1207.

MACBEAN, I. T. AND PARSONS, P. A. 1967. Directional selection for duration of copulation in Drosophila melanogaster. Genetics, 56, 233-239.

MANNING, A. 1959. The sexual behaviour of two sibling Drosophila species. Behaviour, 15, 123-145.

MANNING, A. 1961. The effects of artificial selection for mating speed in Drosophila melanogaster. Anim. Behav., 9, 82-92.

MANNING, A. 1963. Selection for mating speed in Drosophila melanogaster based on the behaviour of one sex. Anim. Behav., 11, 116-120.

MANNING, A. 1967. The control of female receptivity in Drosophila. Anim. Behav., 15, 239-250.

MARKOW, T. A. AND HANSEN, S. A. 1981. Multivariate analysis of Drosophila courtship. Proc. Natl. Acad. Sci., 78, 430-434.

MERRELl, D. J. 1949. Selective mating in Drosophila melanogaster. Genetics, 34, 370-389.

O'DELL, K. M. C. AND BURNET, B. 1988. Effects of the hypoactive and inactive mutants on locomotor activity in Drosophila melanogaster, Heredity 61, 199-207.

O'DELl, K. M. C., COULON, J-F., DAIVID, J. C., PAPIN, C., FUZEAU-BRAESCH, S. AND JALLON, J-M. 1987. La mutation inactive produit une diminution marquee d'octopamine dans le cerveau des Drosophiles. C.R. Seances Soc. Biol. Ser. III, 305, 199-202.

PEChine, J. M., ANTONY, C. AND JALlON, J-M. 1988. Precise characterisation of cuticular compounds in young Drosophila by mass spectrometry. J. Chem. Ecol, 14, 1071-1085.

ROBERTSON, H. M. 1982. Female courtship summation in Drosophila melanogaster, Anim. Behav. 30, 1105-1117.

SIEGEL, R. W., HALL, J. C., GAILEY, D. A. AND KYRIACOU, C. P. 1984. Genetic elements of courtship in Drosophila melanogaster: mosaics and learning mutants. Behav. Genet., 14, 383-410.

SPIESS, E. B. 1970. Mating propensity and its genetic basis in Drosophila melanogaster. In Heckt, M. K. and Steere, W. C. (eds) Essays in Honor of Theodosius Dobzhansky, Appleton Century Crofts, New York, pp. 315-379.

SPIETH, H. T. 1966. Drosophilid mating behaviour: the behaviour of decapitated females. Anim. Behav., 14, 226-235.

STREISINGER, G. 1948. Experiments on sexual isolation in Drosophila. IX. Behaviour of males with etherized females. Evolution, 2, 187-188.

STURTEVANT, A. H. 1915. Experiments on sex recognition and the patterns of sexual selection in Drosophila. J. Anim. Behav., 5, 351-366.

TAN, C. C. 1946. Genetics of sexual isolation between Drosophila pseudoobscura and Drosophila persimilis. Genetics, 31, 558-573.

TOMPKINS, L., GROSS, A. C., HALL, J. C., GAILEY, D. A. AND SIEGAL, R. W. 1982. The role of female movement in the sexual behaviour of Drosophila melanogaster. Behav. Genet., 12, 295-307.

WOOD, D., RINGO, J. M. AND JOHNSON, L. L. 1980. Analysis of courtship sequence of the hybrids between Drosophila melanogaster and Drosophila simulans. Behav. Genet., 10, 459-466. 